\title{
Relationship between Chronic Kidney Disease and Depression in Elderly Koreans Using the 2013 Korea National Health and Nutrition Examination Survey Data
}

\author{
Ji Woon Kim, Sung Jin Moon, Hyun Ja Kim, Dae Geun Lee* \\ Department of Family Medicine, Gyeonggi Province Medical Center Uijeongbu Hospital, Uijeongbu, Korea
}

\begin{abstract}
Background: Depression is prevalent in patients with chronic kidney disease (CKD) and continues to increase in elderly adults. Therefore, the aim of our study was to examine the relationship between CKD and depression in older patients.

Methods: We conducted a cross-sectional study based on 2013 Korea National Health and Nutrition Examination Survey data. In total, data of 973 subjects aged $\geq 65$ years were analyzed, and the estimated glomerular filtration rate (eGFR) was calculated using the Chronic Kidney Disease Epidemiology Collaboration equation.

Results: The prevalence of depression in older adults was $4.1 \%$ in men and $8.8 \%$ in women ( $\mathrm{P}=0.004)$. The prevalence of depression did not differ according to CKD stage in women (normal eGFR and CKD stages 1 and 2 women, 41/474 [8.6\%]) vs. CKD stages 3-5 women, 6/63 [9.5\%]); however, the prevalence of depression in men with CKD stages 3-5 (8/83 [9.6\%]) was significantly higher than in men with normal eGFR and CKD stage 1 and 2 (10/353 [2.8\%], $\mathrm{P}=0.010$ ). Multivariate logistic regression analysis showed that the odds ratio for depression in men with CKD stages 3-5 was 3.822 (95\% confidence interval, 1.229 to 11.879 ) after adjusting for social status and chronic diseases $(\mathrm{P}=0.021)$.

Conclusion: The prevalence of depression was higher in elderly women than in men, while the prevalence of depression increased in elderly men with CKD stages 3-5 and was almost equal to that of women. Therefore, elderly men with progressive renal function impairment should be counseled and monitored for psychological problems.
\end{abstract}

Keywords: Chronic Kidney Diseases; Depression; Elderly; Men 


\section{INTRODUCTION}

Chronic kidney disease (CKD) is highly prevalent and affects about $10 \%$ of the global population. ${ }^{1-3)}$ The prevalence and incidence of renal replacement therapy has increased dramatically and the rate of increase is expected to be over $47 \%$ by $2020{ }^{4)}$ Nearly one-third of community-dwelling adults $>70$ years old meet the criteria for CKD when it is defined as an estimated glomerular filtration rate (eGFR) of $<60$ $\mathrm{mL} / \mathrm{min} / 1.73 \mathrm{~m}^{2}$. ${ }^{\text {s) }}$ Older adults also experience higher rates of eGFR $<30 \mathrm{~mL} / \mathrm{min} / 1.73 \mathrm{~m}^{2}$ than do younger adults, in part due to higher rates of diabetes and hypertension. ${ }^{6)}$ In addition to the traditional risk factors for initiating dialysis, such as cardiovascular disease, proteinuria, and diabetes, there is an increasing interest in psychosocial risk factors. $^{7)}$

The elderly population in developing and developed countries worldwide is increasing gradually due to a prolonged life expectancy. ${ }^{8)}$ At the same time, mental health problems in elderly adults have become a significant public policy concern. The prevalence of major depressive disorder in Korea ranges from $4.3 \%$ to $9.1 \%$, and that of depressive symptoms ranges from $9.1 \%$ to $33.0 \% .^{9)}$ In addition to its increasing prevalence in older adults, depression impacts older people's lives in a different manner than it affects younger people. Depression often occurs in elderly people with other illnesses and disabilities, and it is more prolonged. In addition, advancing age is often accompanied by a loss of social support systems due to the death of a spouse or siblings, retirement, or relocation of residence. Because of changing circumstances and because elderly people are expected to become less active, doctors and family members may miss the signs of depression. ${ }^{10,11)}$ As a result, effective treatment is often delayed, forcing many elderly people to struggle with depression unnecessarily.

The prevalence of depression in patients with CKD ranges from $7 \%$ $42 \%$, which is higher than the prevalence seen in other chronic diseases and, as a result, is the most common psychological problem in patients with CKD. ${ }^{12,13)}$ Several studies in Western countries have investigated the effects of CKD, or end-stage renal disease (ESRD), on depression and found that these conditions are independently associated with a marked increase of both morbidity and mortality. ${ }^{14)}$ Furthermore, patients with a clinical diagnosis of depression, who are undergoing long-term hemodialysis therapy, are twice as likely to die or require hospitalization within one year compared to those without depression. ${ }^{15,16)}$ A diagnosis of depression in patients with ESRD is independently associated with $30 \%$ increases in both cumulative hospital days and the number of hospitalizations, which, in turn, contributes to increased Medicare costs. ${ }^{17)}$

Therefore, our aim was to study the relationship between CKD and depression in elderly Korean adults and further evaluate sex-based differences using data from the Korea National Health and Nutrition Examination Survey (KNHANES).

\section{METHODS}

\section{Study Participants and Database}

We used secondary data from the 2013 KNHANES. The KNHANES is a nationwide representative cross-sectional survey designed to examine dietary habits, lifestyle behaviors, and the overall physical and mental health of the general Korean population. KNHANES was initiated by the Ministry of Health and Welfare in 1998. Annually, 10,000-12,000 individuals from 4,600 households are selected to represent Koreans aged $\geq 18$ years using a multi-stage clustered and stratified random sampling method based on national census data.

Of the 8,018 participants, we excluded subjects $<65$ years old $(n=6,633)$, those with no serum creatinine ( $\mathrm{sCr}$ ) data $(\mathrm{n}=358)$, and those with missing data on depression $(n=44)$. Thus, the final analysis included 973 subjects ( 436 men and 537 women) aged $\geq 65$ years (Figure 1).

\section{Chronic Kidney Disease Stages}

eGFR, expressed in $\mathrm{mL} / \mathrm{min} / 1.73 \mathrm{~m}^{2}$, was calculated using the Chronic Kidney Disease Epidemiology Collaboration (CKD-EPI) equation: ${ }^{18,19)}$ for females with a sCr level $\leq 0.7 \mathrm{mg} / \mathrm{dL}, \mathrm{GFR}=144 \times(\mathrm{sCr} / 0.7)^{-0.329} \times(0.993)$ ${ }^{\text {age}}$; for females with a sCr level $>0.7 \mathrm{mg} / \mathrm{dL}, \mathrm{GFR}=144 \times(\mathrm{sCr} / 0.7)^{-1.209} \times$ $(0.993)^{\text {age }}$; for males with a sCr level $\leq 0.9 \mathrm{mg} / \mathrm{dL}, \mathrm{GFR}=141 \times(\mathrm{sCr} / 0.9)^{-0.411}$ $\times(0.993)^{\mathrm{age}}$; and for males with a sCr level $>0.9 \mathrm{mg} / \mathrm{dL}, \mathrm{GFR}=141 \times$ $(\mathrm{sCr} / 0.9)^{-1.209} \times(0.993)^{\text {age }}$. Participants with CKD (structural kidney or urinary abnormalities with or without a decreased GFR) were classified according to the system suggested in the Kidney Disease Outcome Quality Initiative of 2002. ${ }^{17)}$ Due to the small sample sizes, subjects with kidney function stages 3-5 were combined into one group, leaving the following GFR groups for comparative analyses: normal eGFR and CKD stage 1, eGFR $\geq 90$; CKD stage 2, eGFR 60-89.9; and CKD stages $3-5$, eGFR $<60 \mathrm{~mL} / \mathrm{min} / 1.73 \mathrm{~m}^{2}$.

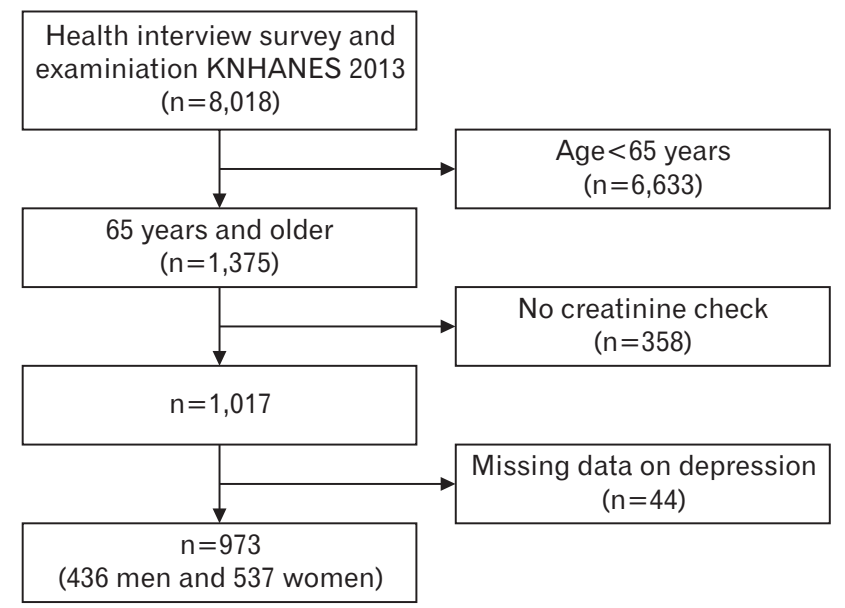

Figure 1. Flow diagram for inclusion and exclusion of study participants. KNHANES, Korea National Health and Nutrition Examination Survey. 


\section{Measurements and Definitions of General and Clinical Characteristics}

For the present study, height, weight, and blood pressure (BP) measurements were obtained. Body mass index (BMI) was calculated by dividing weight $(\mathrm{kg})$ by height squared $\left(\mathrm{m}^{2}\right)$ and all blood samples were collected in the morning following an overnight fast. Smoking status was categorized into two groups ('yes': those who were currently smoking and those who had smoked 100 or more cigarettes in their lifetime; and 'no': non-smokers, ex-smokers, and those who had smoked in the past but ceased), alcohol consumption status was defined as drinking more than once per month, and physical activity (PA) was determined using the Korean version of the International Physical Activity Questionnaire (IPAQ) by asking participants how often they engaged in exercise each week. ${ }^{20)}$ Using the IPAQ, an average metabolic equivalent of task (MET) score was derived for each type of activity, and the following values were used for the analysis of IPAQ data: walking=3.3 METs, moderate $\mathrm{PA}=4.0 \mathrm{METs}$, and vigorous $\mathrm{PA}=8.0 \mathrm{METs}$. Using these values, four continuous scores were defined as walking MET$\mathrm{min} / \mathrm{wk}=3.3 \times$ walking minutes $\times$ walking days, moderate MET-min/ $\mathrm{wk}=4.0 \times$ moderate-intensity activity minutes $\times$ moderate days, vigorous MET- $\mathrm{min} / \mathrm{wk}=8.0 \times$ vigorous-intensity activity minutes $\times$ vigorousintensity days, and total PA MET-min/wk=sum of walking+moderate+ vigorous MET-min/wk scores.
Other medical conditions were defined by the KNHANES analysis guidelines as described below. ${ }^{21)}$ Hypertension was defined as a systolic BP of $\geq 140 \mathrm{~mm} \mathrm{Hg}$, a diastolic BP of $\geq 90 \mathrm{~mm} \mathrm{Hg}$, or the current use of antihypertensive medications. Diabetes mellitus was defined as a plasma glucose level $\geq 126 \mathrm{mg} / \mathrm{dL}$ after at least 8 hours of fasting or diabetes treatment with either an oral hypoglycemic agent or insulin. Cardiovascular disease was defined as a history of angina pectoris or myocardial infarction.

Depression was defined as an answer of "yes" to the question of whether they had been diagnosed with depression by their doctor. In the KNHANES analysis, depressive symptoms were assessed with the following question: "In the past year, have you felt extremely sorrowful or despair for more than 2 weeks?", which was answered with a "yes" or "no". This questionnaire has been used to identify people with depressive mood since the start of the KNHANES in 1998. Additionally, the participants were asked whether they ever had a diagnosis of clinical depression confirmed by physicians, and those who answered "yes" reported their age at first diagnosis. The question regarding depressive symptoms has been widely used to assess participants and is considered to be a proxy for depressive disorder ${ }^{22)}$ with a sensitivity of $86 \%$, a specificity of $78 \%$, and a positive and negative predictive value of $82 \%$ for the diagnosis of depression. ${ }^{23)}$ To ensure an accurate analysis, only participants who were diagnosed with depression by physi-

Table 1. Clinical characteristics of Koreans aged $\geq 65$ years according to depression

\begin{tabular}{|c|c|c|c|c|c|c|}
\hline \multirow[b]{2}{*}{ Characteristic } & \multicolumn{3}{|c|}{ Men $(n=436)$} & \multicolumn{3}{|c|}{ Women $(n=537)$} \\
\hline & $\begin{array}{l}\text { Without depression } \\
\qquad(\mathrm{n}=418)\end{array}$ & $\begin{array}{l}\text { With depression } \\
\qquad(n=18)\end{array}$ & P-value* & $\begin{array}{l}\text { Without depression } \\
\qquad(\mathrm{n}=490)\end{array}$ & $\begin{array}{l}\text { With depression } \\
\quad(n=47)\end{array}$ & P-value \\
\hline Age $(y)$ & $71.2 \pm 4.8$ & $73.1 \pm 5.8$ & 0.344 & $71.7 \pm 5.0$ & $70.4 \pm 4.1$ & 0.07 \\
\hline Body mass index $\left(\mathrm{kg} / \mathrm{m}^{2}\right)$ & $23.4 \pm 2.8$ & $23.8 \pm 2.8$ & 0.751 & $24.5 \pm 3.3$ & $25.0 \pm 2.6$ & 0.316 \\
\hline Income (<middle) & $204(49.2)$ & $12(66.7)$ & 0.158 & $245(50.5)$ & $21(44.7)$ & 0.542 \\
\hline Education (<middle) & $261(62.6)$ & $11(61.1)$ & 0.541 & $428(87.3)$ & $43(91.5)$ & 0.494 \\
\hline Marital status & 416 (99.5) & $18(100)$ & 0.958 & $486(99.2)$ & $47(100)$ & 0.999 \\
\hline Hypertension & $189(45.2)$ & 13 (72.2) & 0.03 & $222(45.3)$ & $23(48.9)$ & 0.649 \\
\hline Diabetes mellitus & $86(20.6)$ & 4 (22.2) & 0.773 & 377 (76.9) & $37(78.7)$ & 0.858 \\
\hline Stroke & $28(6.7)$ & $2(11.1)$ & 0.356 & $26(5.3)$ & $3(6.4)$ & 0.733 \\
\hline Cardiovascular disease & $35(8.4)$ & $3(16.7)$ & 0.200 & $31(6.3)$ & $5(10.6)$ & 0.230 \\
\hline Smoking & $91(21.8)$ & $4(22.2)$ & 0.452 & $230(47.1)$ & $24(51.0)$ & 0.990 \\
\hline Alcohol & $159(38.0)$ & $7(38.9)$ & 0.412 & $136(27.8)$ & $16(34.0)$ & 0.512 \\
\hline Physical activity ${ }^{\dagger}$ (metabolic equivalent-min/wk) & $3.13 \pm 0.46$ & $3.08 \pm 0.56$ & 0.704 & $2.86 \pm 0.48$ & $2.99 \pm 0.49$ & 0.104 \\
\hline White blood cell count $\left(/ \mathrm{mm}^{3}\right)$ & $6.22 \pm 1.79$ & $6.44 \pm 1.50$ & 0.826 & $6.00 \pm 1.82$ & $6.24 \pm 1.77$ & 0.640 \\
\hline Hemoglobin $(\mathrm{g} / \mathrm{dL})$ & $14.5 \pm 1.2$ & $15.2 \pm 1.2$ & 0.918 & $13.1 \pm 1.1$ & $13.1 \pm 0.9$ & 0.152 \\
\hline Fasting glucose (mg/dL) & $105.6 \pm 20.6$ & $108.1 \pm 16.9$ & 0.845 & $105.8 \pm 24.5$ & $102.3 \pm 21.1$ & 0.377 \\
\hline Total cholesterol (mg/dL) & $181.9 \pm 35.3$ & $179.2 \pm 39.6$ & 0.664 & $195.7 \pm 37.2$ & $197.7 \pm 38.1$ & 0.580 \\
\hline Triglyceride (mg/dL) & $130.6 \pm 91.5$ & $172.2 \pm 90.4$ & 0.499 & $145.2 \pm 77.6$ & $143.2 \pm 54.3$ & 0.093 \\
\hline High-density lipoprotein cholesterol (mg/dL) & $48.5 \pm 12.8$ & $47.3 \pm 16.1$ & 0.470 & $50.0 \pm 10.8$ & $50.9 \pm 11.9$ & 0.521 \\
\hline $\mathrm{eGFR}\left(\mathrm{mL} / \mathrm{min} / 1.73 \mathrm{~m}^{2}\right)$ & $75.1 \pm 14.8$ & $68.5 \pm 22.2$ & $<0.001$ & $78.7 \pm 14.0$ & $76.4 \pm 13.3$ & 0.323 \\
\hline Chronic kidney disease stage & & & 0.013 & & & 0.504 \\
\hline Normal eGFR and stage 1 & $58(13.9)$ & $3(16.7)$ & & $109(22.2)$ & $7(14.9)$ & \\
\hline Stage 2 & $285(68.2)$ & $7(38.9)$ & & $324(66.1)$ & $34(72.3)$ & \\
\hline Stages 3-5 & $75(17.9)$ & $8(44.4)$ & & $57(11.6)$ & $6(12.8)$ & \\
\hline
\end{tabular}

Values are presented as mean \pm standard deviation or number (\%).

eGFR, estimated glomerular filtration rate.

*By chi-square test for categorical variables, t-test for continuous variables. ${ }^{\dagger}$ Physical activity: log transformed. 
cians (the latter question) were included in the study.

\section{Ethical Considerations}

All patients in the KNHANES signed an informed consent form. Because this was a cross-sectional study based on KNHANES (http:// knhanes.cdc.go.kr/knhanes/), ethical approval was not required.

\section{Statistical Analysis}

The statistical analysis was performed using IBM SPSS for Windows ver. 20.0 software (IBM Corp., Armonk, NY, USA). A complex sample analysis was performed based on an analysis plan file in which weights, stratification variables, and primary sampling units were designed. Continuous variables are expressed as mean \pm standard deviation and were compared using Student t-test. Categorical variables are expressed as proportions and were compared using the chi-square test. To identify the independent factors associated with depression, a complex sample logistic regression analysis was performed to identify associations between the stage of CKD and depression after controlling for covariates, such as income level, education level, marital status, hypertension, diabetes mellitus, smoking, alcohol, and PA. Due to skewed distributions, PA was log-transformed prior to the multivariate analysis. P-values $<0.05$ were considered to indicate statistical significance.

\section{RESULTS}

\section{Clinical and Demographic Characteristics}

The clinical characteristics of this sample of Koreans aged $\geq 65$ years according to their depression status are provided in Table 1 . The mean ages of those without and with depression were 71.2 and 73.1 years, respectively, in men, and 71.1 and 70.4 years, respectively, in women. A total of 65 of the 973 patients (6.7\%) were diagnosed with depression. The prevalence of depression was more than two-fold higher in women than that in men (47/537 [8.8\%] and 18/436 [4.1\%], respectively).
BMI, income level, educational status, marital status, smoking, alcohol, PA, chronic diseases such as hypertension and diabetes mellitus, and CKD stage were not related to depression in women. Alternatively, the prevalence of depression in men with CKD stages 3-5 was higher than that observed in men with a normal eGFR and CKD stages 1 and 2 (8/18 [44.4\%] versus 75/418 [17.9\%], respectively; $\mathrm{P}=0.013)$.

\section{Prevalence of Depression According to Chronic Kidney Disease Stage in Men and Women}

Figure 2 shows the prevalence of depression according to CKD stage. The prevalence rates of depression were 51/827 (6.2\%) and 14/146 (9.6\%), respectively, in the normal eGFR, and CKD stage 1 and 2 group and in the CKD stages 3-5 group for all patients $(\mathrm{P}=0.148)$. The prevalence rates of depression did not differ according to CKD stage in women (41/474 [8.6\%] in the normal eGFR and CKD stages 1 and 2 group versus $6 / 63$ [9.5\%] the $\mathrm{CKD}$ stages $3-5$ group; $\mathrm{P}=0.812$ ) while the prevalence of depression in men with CKD stages 3-5 (8/83 [9.6\%]) was significantly higher than that in men with normal eGFR and CKD stages 1 and 2 group (10/353 [2.8\%], $\mathrm{P}=0.010)$. The prevalence of depression increased in elderly men as the kidney function worsened.

\section{Multivariate Logistic Regression Analysis of Chronic Kidney Disease and Depression}

We conducted logistic analyses to investigate the association between CKD stage and depression. In men, the adjusted odds ratio (OR; 95\% confidence interval [CI]) for depression in the CKD stages 3-5 group was 3.822 (1.229-11.879) compared to the normal eGFR and CKD stage 1 group $(\mathrm{P}=0.021)$ (Table 2). However, the OR for depression in the CKD stage 3-5 group was not significant in women (OR, 0.973; 95\% CI, 0.245 to $3.872 ; \mathrm{P}=0.969$ ). CKD stages $3-5$ were significantly associated with depression in elderly men.
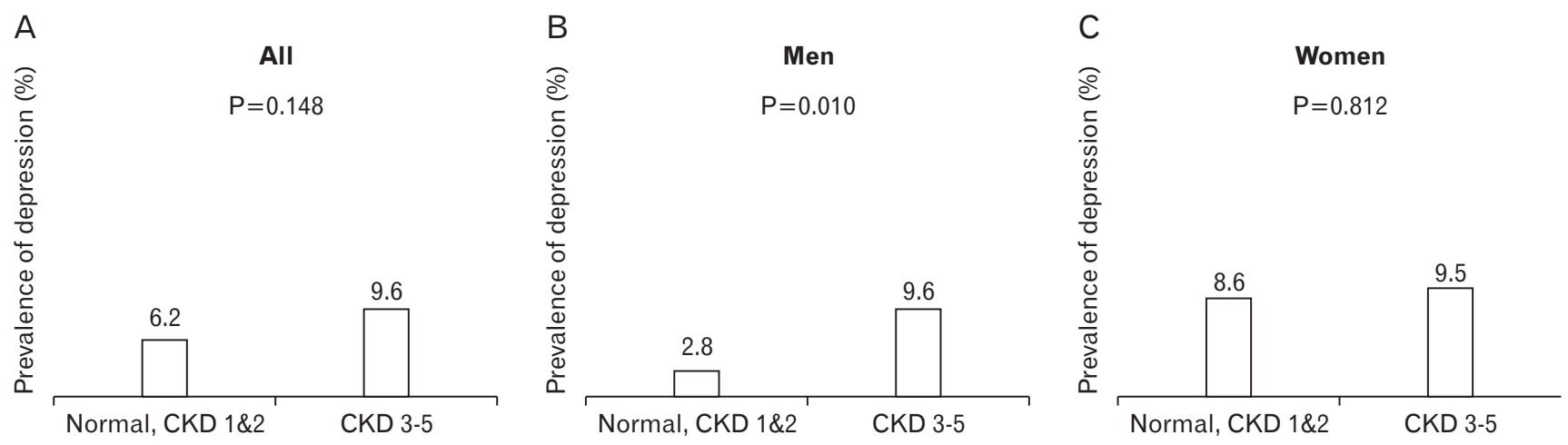

Figure 2. Prevalence of depression according to CKD stage. (A) The prevalence rates of depression were 51/827 (6.2\%) and 14/146 (9.6\%), respectively, in the normal eGFR and CKD stages 1 and 2 group and in the CKD stages 3-5 group for all patients ( $P=0.148)$. (B) The prevalence rates of depression were 10/353 (2.8\%) and 8/83 (9.6\%), respectively, in the normal eGFR and CKD stages 1 and 2 group and in the CKD stages $3-5$ group in men ( $P=0.010)$. (C) The prevalence rates of depression were $41 / 474$ $(8.6 \%)$ and $6 / 63(9.5 \%)$, respectively, in the normal eGFR and CKD stage 1 and 2 group and in the CKD stages $3-5$ group in women ( $P=0.812)$. CKD, chronic kidney disease; eGFR, estimated glomerular filtration rate. 
Table 2. Multivariate analysis of the baseline parameters associated with depression

\begin{tabular}{|c|c|c|c|c|}
\hline \multirow{2}{*}{ Variable } & \multicolumn{2}{|c|}{ Men } & \multicolumn{2}{|c|}{ Women } \\
\hline & $\mathrm{OR}(95 \% \mathrm{Cl})$ & P-value & OR $(95 \% \mathrm{Cl})$ & P-value \\
\hline CKD stages 3-5 & $3.822(1.229-11.879)$ & 0.021 & $0.973(0.245-3.872)$ & 0.969 \\
\hline Income (<middle) & $0.824(0.201-3.382)$ & 0.276 & $1.317(0.483-3.595)$ & 0.731 \\
\hline Education (<middle) & $0.812(0.225-2.931)$ & 0.494 & $1.259(0.286-5.541)$ & 0.570 \\
\hline Marital status & - & 0.999 & - & 0.999 \\
\hline Hypertension & $1.752(0.347-8.836)$ & 0.852 & $1.341(0.482-3.737)$ & 0.732 \\
\hline Diabetes mellitus & $0.384(0.068-2.167)$ & 0.882 & $1.244(0.355-4.360)$ & 0.795 \\
\hline Smoking & $1.172(0.319-4.306)$ & 0.809 & $0.591(0.024-14.595)$ & 0.727 \\
\hline Alcohol & $0.692(0.181-2.649)$ & 0.856 & $0.996(0.350-2.839)$ & 0.994 \\
\hline Physical activity* & $1.101(0.348-3.483)$ & 0.868 & $0.440(0.149-1.299)$ & 0.136 \\
\hline
\end{tabular}

The stages of CKD were divided according to eGFR: normal eGFR and CKD stage 1 (eGFR, $\geq 90 \mathrm{~mL} / \mathrm{min} / 1.73 \mathrm{~m}^{2}$ ), CKD stage 2 (eGFR, 60-89.9 mL/min/1.73 m²), and CKD stages 3-5 (eGFR, $<60 \mathrm{~mL} / \mathrm{min} / 1.73 \mathrm{~m}^{2}$ ).

$\mathrm{OR}$, odds ratio; $\mathrm{Cl}$, confidence interval; $\mathrm{CKD}$, chronic kidney disease; eGFR, estimated glomerular filtration rate.

*Physical activity: log transformed.

\section{DISCUSSION}

This study provides a meaningful comparison of the prevalence of depression according to sex in elderly patients with CKD. The prevalence of depression was higher in women, regardless of CKD stage. However, the prevalence of depression increased in men as CKD stage increased (2.8\% versus $9.6 \%$ in normal eGFR and CKD stages $1-2$ versus CKD stages 3-5, respectively; $\mathrm{P}=0.010$ ) (Figure 2). These results suggest that physicians should be aware of depression in men, as well as women patients, with CKD, particularly in elderly patients. Many studies have shown that major depression or depressive symptoms are associated with late-stage CKD, such as that reported in patients with ESRD on hemodialysis. ${ }^{24,25)}$ However, few data are available on the prevalence of depression in patients with earlier stages of CKD, before dialysis therapy is initiated. We investigated the relationship between all stages of CKD and depression, with a focus on elderly people.

It has been repeatedly shown that women are at greater risk for depression than men, and the female-to-male prevalence ratio for depression has been widely accepted to be approximately $2: 1{ }^{8)}$ Our results ( $4.1 \%$ versus $8.8 \%$ in men and women, respectively) for patients with all stages of CKD are consistent with this generally accepted ratio. However, some studies showed that this may be an artifact that reflects a greater tendency for women to seek help or over-report depressive symptoms compared with men. ${ }^{8)}$ Furthermore, women may be more apt to dwell on their stress and turn transient negative emotions into severe depressive symptoms, whereas men tend to minimize their depressive mood and engage in more active behaviors. ${ }^{26)}$ Interestingly, our results show that the prevalence of depression in men with impaired renal function (CKD stages 3-5) increased and was approximately equal to that seen in women (9.6\% versus $9.5 \%$, respectively). This result might reflect an association between more severe comorbidities and more depressive symptoms.

The present study also found an independent association between CKD stage and an increased risk of depression in elderly men with decreased kidney function, even after adjusting for other common co- morbidities such as diabetes, hypertension, and lifestyle factors such as smoking, alcohol, and PA. It is possible that those in the lower eGFR category experienced symptoms more directly related to their kidney disease, including dyspnea, poor appetite, or fatigue, which might affect depression.

The potential mechanisms responsible for the association between depression and adverse clinical outcomes are not completely clear. One plausible mechanism is non-adherence to medical regimens, which has been observed in hemodialysis patients with depression who were shown to be less compliant with dietary and fluid restrictions. ${ }^{27)}$ Some evidence suggests that depression may be associated with factors that could predispose patients to develop cardiac disease, such as lower heart rate variability, ${ }^{28)}$ increased cortisol and norepinephrine excretion, ${ }^{29)}$ and an altered immunological or stress response. ${ }^{30)}$ Some studies show that patients with depression and ESRD have higher circulating levels of interleukin-6, tumor necrosis factor- $\alpha$, and C-reactive protein, which are associated with poor outcomes. ${ }^{31,32)}$ Depression is also associated with poorer nutrition and leads to an upregulation of inflammatory mediators. ${ }^{33)}$

Even in the absence of a clear causal mechanism, several actions can be taken to improve clinical outcomes. Tsai et al. ${ }^{13)}$ suggested that patients with CKD can be screened for depressive symptoms using the Beck Depression Inventory, particularly when a psychiatric consultation is unavailable or stigmatizing to the patient. This screening tool may help uncover a psychiatric illness and identify patients at high risk for depression. They also suggested that the care team begin preparation for ESRD earlier, and that referral to a nephrologist should be considered at an earlier stage, considering the possibility of rapid progression. $^{13)}$

Our study has several limitations. First, the cross-sectional nature of the study made it impossible to assess any cause-and-effect relationships. Further prospective research is warranted to better assess the causal relationship between kidney function and depression in men. Second, eGFR was calculated using the CKD-EPI equation, which involves age, sex, and sCr level. However, sCr is affected by muscle mass. 
If the eGFR equation using cystatin-C rather than $\mathrm{Cr}$ had been used, the result would likely have been more accurate. Third, we did not separate patients with CKD stage 5 from those who were not undergoing hemodialysis. Finally, we could not exclude the effects of information bias because of the nature of the survey questionnaire. However, this study also had several strengths. Population-based nationwide representative data obtained by the KNHANES were used for this study. Therefore, a stratified multistage probability sampling method was used to obtain representative data of South Korean adults using a large sample size.

In conclusion, the prevalence of depression was higher in elderly women than in elderly men. However, the prevalence of depression in men with CKD stages 3-5 increased to almost the same prevalence as that seen in women. Therefore, elderly men with progressively impaired renal function should be counseled and monitored carefully. Further studies may be necessary to investigate the causal factors and methods to prevent and treat depression in elderly patients with kidney disease.

\section{CONFLICT OF INTEREST}

No potential conflict of interest relevant to this article was reported.

\section{REFERENCES}

1. Coresh J, Byrd-Holt D, Astor BC, Briggs JP, Eggers PW, Lacher DA, et al. Chronic kidney disease awareness, prevalence, and trends among U.S. adults, 1999 to 2000. J Am Soc Nephrol 2005;16:180-8.

2. Chen J, Wildman RP, Gu D, Kusek JW, Spruill M, Reynolds K, et al. Prevalence of decreased kidney function in Chinese adults aged 35 to 74 years. Kidney Int 2005;68:2837-45.

3. Levey AS, Coresh J, Balk E, Kausz AT, Levin A, Steffes MW, et al. National Kidney Foundation practice guidelines for chronic kidney disease: evaluation, classification, and stratification. Ann Intern Med 2003;139:137-47.

4. National Institutes of Health. United States Renal Data System annual data report: atlas of end-stage renal disease in the United States. Bethesda (MD): National Institutes of Health, National Institute of Diabetes and Digestive and Kidney Diseases; 2009.

5. Coresh J, Selvin E, Stevens LA, Manzi J, Kusek JW, Eggers P, et al. Prevalence of chronic kidney disease in the United States. JAMA 2007;298:2038-47.

6. Collins AJ, Foley RN, Herzog C, Chavers B, Gilbertson D, Ishani A, et al. US Renal Data System 2010 annual data report. Am J Kidney Dis 2011;57(1 Suppl 1):A8, e1-526.

7. McKercher CM, Venn AJ, Blizzard L, Nelson MR, Palmer AJ, Ashby MA, et al. Psychosocial factors in adults with chronic kidney disease: characteristics of pilot participants in the Tasmanian Chronic Kidney Disease study. BMC Nephrol 2013;14:83.

8. Shah A. The relationship between suicide rates and age: an analysis of multinational data from the World Health Organization. Int Psychogeriatr 2007;19:1141-52.

9. Cho MJ, Lee JY, Kim BS, Lee HW, Sohn JH. Prevalence of the major mental disorders among the Korean elderly. J Korean Med Sci 2011;26:1-10.

10. Chang-Quan H, Xue-Mei Z, Bi-Rong D, Zhen-Chan L, Ji-Rong Y, QingXiu L. Health status and risk for depression among the elderly: a metaanalysis of published literature. Age Ageing 2010;39:23-30.

11. Niti M, Ng TP, Kua EH, Ho RC, Tan CH. Depression and chronic medical illnesses in Asian older adults: the role of subjective health and functional status. Int J Geriatr Psychiatry 2007;22:1087-94.

12. Balogun RA, Abdel-Rahman EM, Balogun SA, Lott EH, Lu JL, Malakauskas SM, et al. Association of depression and antidepressant use with mortality in a large cohort of patients with nondialysis-dependent CKD. Clin J Am Soc Nephrol 2012;7:1793-800.

13. Tsai YC, Chiu YW, Hung CC, Hwang SJ, Tsai JC, Wang SL, et al. Association of symptoms of depression with progression of CKD. Am J Kidney Dis 2012;60:54-61.

14. Hedayati SS, Bosworth HB, Briley LP, Sloane RJ, Pieper CF, Kimmel PL, et al. Death or hospitalization of patients on chronic hemodialysis is associated with a physician-based diagnosis of depression. Kidney Int 2008;74:930-6.

15. Palmer SC, Vecchio M, Craig JC, Tonelli M, Johnson DW, Nicolucci A, et al. Association between depression and death in people with CKD: a meta-analysis of cohort studies. Am J Kidney Dis 2013;62:493-505.

16. Kellerman QD, Christensen AJ, Baldwin AS, Lawton WJ. Association between depressive symptoms and mortality risk in chronic kidney disease. Health Psychol 2010;29:594-600.

17. Hedayati SS, Grambow SC, Szczech LA, Stechuchak KM, Allen AS, Bosworth HB. Physician-diagnosed depression as a correlate of hospitalizations in patients receiving long-term hemodialysis. Am J Kidney Dis 2005;46:642-9.

18. Levey AS, Stevens LA, Schmid CH, Zhang YL, Castro AF 3rd, Feldman $\mathrm{HI}$, et al. A new equation to estimate glomerular filtration rate. Ann Intern Med 2009;150:604-12.

19. National Kidney Foundation. K/DOQI clinical practice guidelines for chronic kidney disease: evaluation, classification, and stratification. Am J Kidney Dis 2002;39(2 Suppl 1):S1-266.

20. Chun MY. Validity and reliability of Korean version of international physical activity questionnaire short form in the elderly. Korean J Fam Med 2012;33:144-51.

21. Kim NS, Ahn J, Lee BK, Park J, Kim Y. Environmental exposures to lead, mercury, and cadmium among South Korean teenagers (KNHANES 2010-2013): body burden and risk factors. Environ Res 2017;156:46876.

22. Park SJ, Jeon HJ, Kim JY, Kim S, Roh S. Sociodemographic factors associated with the use of mental health services in depressed adults: results from the Korea National Health and Nutrition Examination Survey (KNHANES). BMC Health Serv Res 2014;14:645.

23. Watkins C, Daniels L, Jack C, Dickinson H, van Den Broek M. Accuracy of a single question in screening for depression in a cohort of patients after stroke: comparative study. BMJ 2001;323:1159.

24. Kimmel PL, Cukor D, Cohen SD, Peterson RA. Depression in endstage renal disease patients: a critical review. Adv Chronic Kidney Dis 2007;14:328-34.

25. Cukor D, Coplan J, Brown C, Friedman S, Cromwell-Smith A, Peterson RA, et al. Depression and anxiety in urban hemodialysis patients. Clin J Am Soc Nephrol 2007;2:484-90. 
26. Korea National Statistical Office. The aged statistics. Daejeon: Statistics Korea; 2010.

27. Safdar N, Baakza H, Kumar H, Naqvi SA. Non-compliance to diet and fluid restrictions in haemodialysis patients. J Pak Med Assoc 1995;45:293-5.

28. Carney RM, Blumenthal JA, Stein PK, Watkins L, Catellier D, Berkman LF, et al. Depression, heart rate variability, and acute myocardial infarction. Circulation 2001;104:2024-8.

29. Otte C, Marmar CR, Pipkin SS, Moos R, Browner WS, Whooley MA. Depression and 24-hour urinary cortisol in medical outpatients with coronary heart disease: the Heart and Soul Study. Biol Psychiatry 2004;56:241-7.

30. Otte C, Neylan TC, Pipkin SS, Browner WS, Whooley MA. Depressive symptoms and 24-hour urinary norepinephrine excretion levels in patients with coronary disease: findings from the Heart and Soul Study. Am J Psychiatry 2005;162:2139-45.

31. Howren MB, Lamkin DM, Suls J. Associations of depression with C-reactive protein, IL-1, and IL-6: a meta-analysis. Psychosom Med 2009;71:171-86.

32. Simic Ogrizovic S, Jovanovic D, Dopsaj V, Radovic M, Sumarac Z, et al. Could depression be a new branch of MIA syndrome? Clin Nephrol 2009;71:164-72.

33. Bonnet F, Irving K, Terra JL, Nony P, Berthezene F, Moulin P. Anxiety and depression are associated with unhealthy lifestyle in patients at risk of cardiovascular disease. Atherosclerosis 2005;178:339-44. 